\title{
Measured Current Characteristics of Powered E-Textile Transmission Lines with Respect to Welding Process Parameters
}

\author{
Senem Kurşun Bahadır, Umut Kıvanç Şahin \\ Department of Textile Engineering, İstanbul Technical University, 34437, İstanbul, Turkey
}

Corresponding Author: Umut Kıvanç Şahin, sahinumut3@itu.edu.tr

\begin{abstract}
Among the diverse range of techniques applied in manufacturing of wearable electronics, welding process appears to be one of the most promising, as it offers high protection and insulation without sacrificing textile comfort and quality expectations, however, a number of factors including material and processing types must be considered in order to reach a high quality welded e-textile with repeatable and accurate functionality. In this study, in order to create an e-textile power transmission system, stainless steel conductive yarns were welded with three different types of multi-layered breathable, waterproof and windproof welding tapes on top of either polyester or polyamide textile fabrics under different welding process parameters. Current on the e-textile sample was measured and acquired via real-time measurements under different voltages applied. The effects of welding parameters together with material types at various applied voltages on electrical current passing through powered e-textile structure were statistically analyzed and discussed. Interaction of highly effective factors were presented using contour plots. Moreover, a desirability map was prepared for a targeted current. Statistical analysis of the experimental data showed that applied voltage and linear resistance of conductive yarn were the highly significantly effective factors on obtained level of current when the welded e-textile samples are powered. Desirability map showed that by selection of levels of factors applied throughout the study, a targeted actual current level can be reached with a very high precision (over 99\%).
\end{abstract}

\section{ARTICLE HISTORY}

Received: 18.08.2018

Accepted: 26.02.2019

\section{KEYWORDS}

Welding, electronic textiles (etextiles), current, stainless steel conductive yarns, wearable electronics, transmission line, multi-layered welding tapes, desirability map

\section{INTRODUCTION}

In the last few years, wearable electronics are on fashion in the global market. For manufacturing of these medical and electronic devices, conductive threads are commonly used, and those made of stainless steel are proven to be very useful in electro-textile applications where transfer of information or energy is vital for achieving functionality of the designed wearable electronics [1, 2].

Offering advantages in high production, automate processing and high bonding quality, use of welding techniques for interconnection of materials is very common in industries including automobile, shipbuilding, bridge construction as well as textile manufacturing [3-6]. However, welding might be highly unstable, and for an effective and accurate welding process, production parameters as well as materials to be used must be very carefully selected depending on the materials to be welded and the end-use of the final product [7-9].

A number of welding and bonding technologies are commonly used for textiles, including hot air fabric and hot wedge fabric welding, ultrasonic, laser and radio frequency welding [10-13]. In order to obtain welded seams, two techniques are being applied. First one is based on use of a thermoplastic film in bonding two fabrics together, while the second one comprises sticking of the two fabrics on each other via molecular interlocking of the two surfaces at their melting temperatures [1]. Considering the increasing

To cite this article: Kurşun Bahadır, S., Şahin, U.K. 2019. Measured current characteristics of powered e-textile transmission lines with respect to welding process parameters. Tekstil ve Konfeksiyon, 29(2), 97-104. 
number of materials combinations, welding machine types and many other welding factors including welding time, current and force, a high number of criteria must be selected to cover quality expectations from welded seams [14]. Studies about weld line formation on textiles were mostly interested in appropriate selection of factors regarding quality of welded seams, i.e. speed, temperature or pressure applied during welding process, or compatibilities of materials depending on welding technique [15-20].

In this study, three different welding tapes, two different fabrics and four different conductive yarns were used for manufacturing of welded e-textile structures under different welding process parameters in an effort to investigate the characteristics of current when the welded e-textile is powered under varying voltages.

\section{E-TEXTILE SYSTEM AND HOT AIR WELDING PROCEDURE}

In order to create a welded area on the e-textile system composed of conductive yarns which are used for transmission of power, hot air welding system based on hotair heat - transfer mechanism is applied. The conductive yarns passing through welding seam tape and thermoplastic fabric carry power in an e-textile power transmission line system in fabric form as shown in Figure 1.

The welding made on the stainless steel yarn hidden between two thermoplastic fabric type materials is critical in order to prevent possible short circuits caused by environmental effects during usage [21].

Hot air welding uses compressed hot air that passes through a nozzle. The hot air is delivered by shaped or perforated nozzle between two thermoplastic surfaces. In our study, three different welding tapes were used as second thermoplastic layer of the e-textile structure shown in Figure 1. Welding tape is a textile material coated with an adhesive on one or two sides of a textile substrate and when subjected to heat, it sticks on top of the thermoplastic layer on which it stands over [22]. The welding tapes used in our study are correspondingly; WT1 is made from three layers (layer 1-warp knitted fabric, layer 2-waterproof film and layer 3-hot melt adhesive; polyurethane/polyurethane/ polyamide tricot), with a thickness of $368 \mu \mathrm{m}$ and width of 20 $\mathrm{mm}$, while tape WT2 is made from three layers (layer 1warp knitted fabric, layer 2-waterproof film and layer 3hot melt adhesive; polyurethane/polyurethane/polyester jersey) with a thickness of $579 \mu \mathrm{m}$ and width of $20 \mathrm{~mm}$ and WT3 is made from two layers (layer $1-$ waterproof film and layer 2-hot melt adhesive film; polyurethane/polyurethane), with a thickness of $89 \mu \mathrm{m}$ and width of $20 \mathrm{~mm}$. All tapes are breathable, waterproof and windproof. The tapes were chosen in order to prevent probable short circuits during signal transmission, as well as for obtaining a waterresistant fabric structure when considering the usage issues of e-textiles. It is obvious that welding tape type should be carefully selected in order to achieve proper adhesion during manufacturing welded e-textile samples such that the coverage of the base fabric is proper and even throughout the e-textile sample, and packing of the circuit is done properly where minimum gap is left between the welding tape and the base fabric.

Commercial conductive yarns were used to create a transmission line in a two-layered e-textile fabric system. The properties of the conductive yarns used for manufacturing the transmission lines are presented in Table 1. Conductive yarns are placed over the selected fabric, either polyamide or polyester, and covered by the welding tapes WT1, WT2 and WT3 using H\&H Al-001 hot air welding machine. The conductive yarns were positioned along a straight trajectory in the middle of the fabric without any undulation. The transmission line shown in Figure 1 was hidden by the placement of the conductive yarn between the fabric and welding tape during the welding process. Thanks to the unique excellent flexibility, lamination capability and soft hand properties of the welding tapes, slippage of conductive yarns and distortion of overall fabric structure are avoided. Moreover, being manufactured from multilayered thermoplastic films, water leakages are prevented and edge fraying is eliminated by over bonded seams on conductive yarns. The welded e-textile power transmission line samples containing stainless steel conductive yarns are presented in Figure 2.

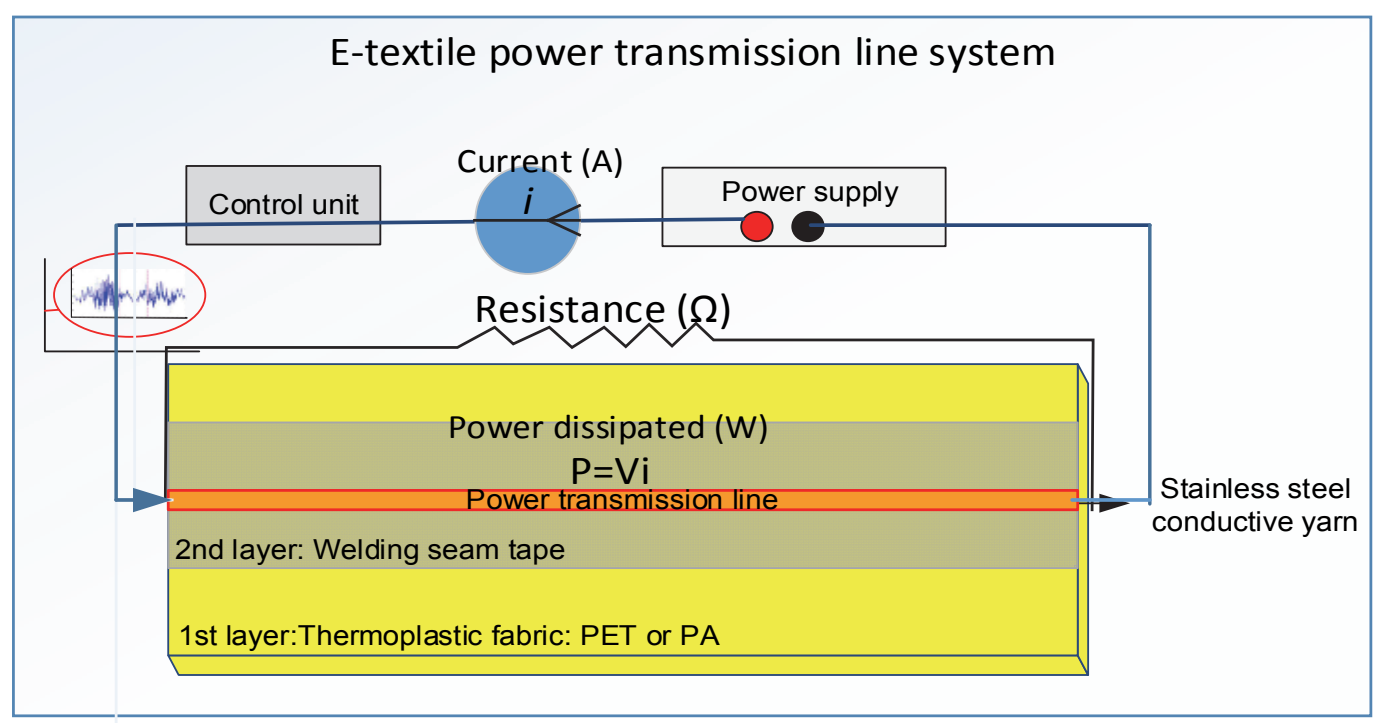

Figure 1. E-textile power transmission line systems 
Table 1. Characteristic of stainless steel conductive yarns

\begin{tabular}{cccc}
\hline Type & Linear Resistance $(\boldsymbol{\Omega} / \mathbf{m})$ & Tensile Strength $(\mathbf{c N})$ & Extension $(\%)$ \\
\hline 1 & 51 & 2287 & 0.91 \\
2 & 30 & 2593 & 0.74 \\
3 & 18 & 2856 & 0.52 \\
4 & 5.4 & 3224 & 0.32 \\
\hline
\end{tabular}

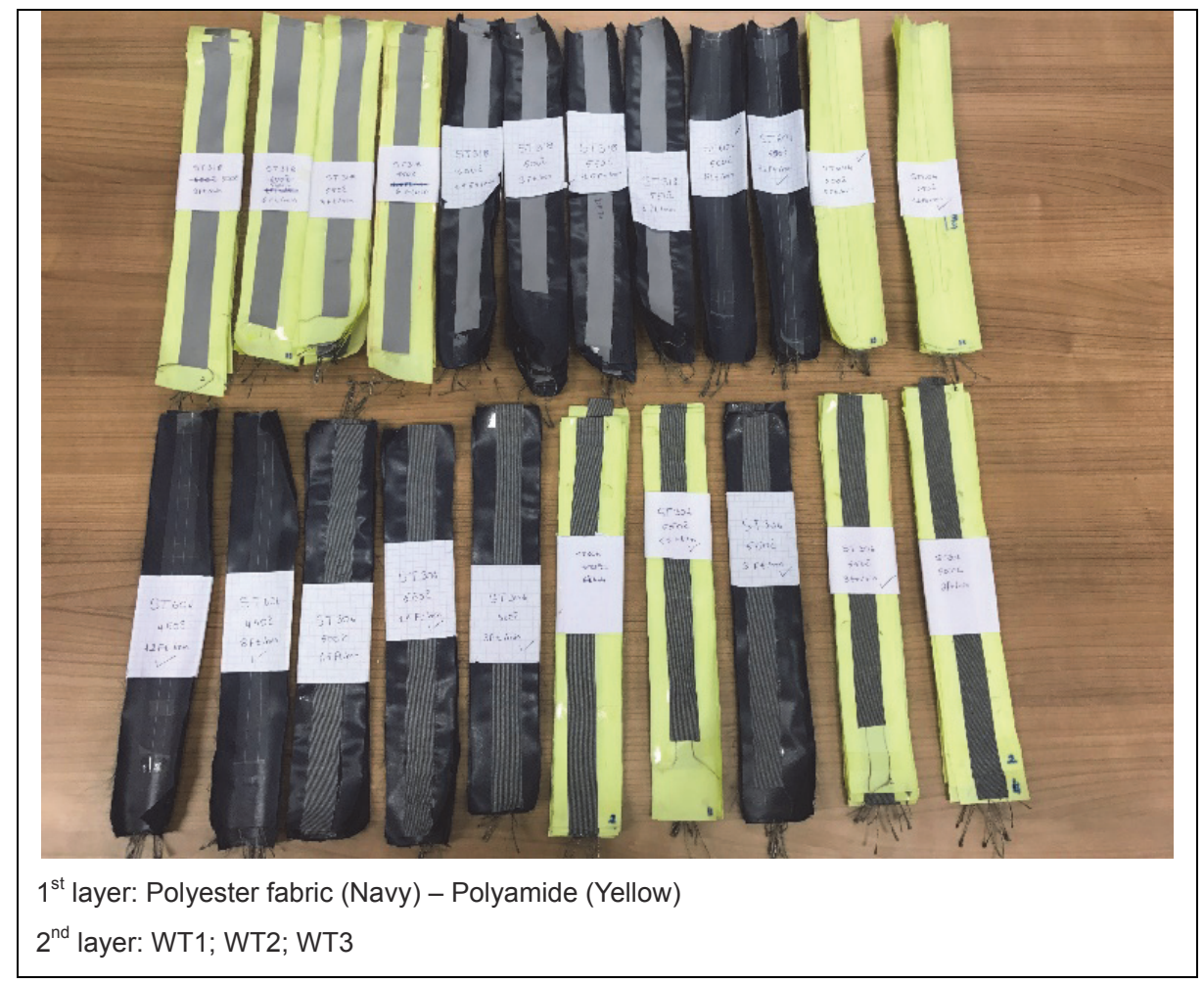

Figure 2. The welded e-textile power transmission line samples

Moreover, in an effort to deeper investigate the effect of welding process parameters on the final measured current of welded e-textile samples when they are subjected to voltage, welding temperature and feeding rate levels were varied. Depending on the fabric and welding tape to be used, welding processing temperatures and feeding rates were carefully selected in order to achieve proper adhesion of the welding tapes while avoiding any harm on either the fabric, the welding tape and the conductive yarn. The levels of processing temperatures $\left[450-550{ }^{\circ} \mathrm{C}\right]$ and feeding rates [1.5-12 ft/min] were carefully selected by preliminary trials. The welding pressure, pressure of hot air and wheel pressure of blow were set up to $0.1,0.65$ and 3.92 bar, respectively, during the welding process of all samples, while welding temperature and feeding speed were varied. The experimental parameters studied with the welding parameters are summarized in Table 2. Totally, 96 welded e-textile samples were manufactured and each tested under three voltage levels in the study.

\section{TESTING SET UP AND CURRENT MEASUREMENT ON WELDED E-TEXTILE POWER LINES}

In order to measure current passing through welded e-textile samples with high precision and repeatability when they are powered, a set up with reference to our previous study [21] has been used (see Figure 3 ). The set up includes an opaque $45^{\circ}$ inclined background block inside a dark testing cubicle. Emissivity value of opaque background block is estimated to have a value of 0.95 . Welded e-textile samples are placed on the opaque block and the ends of samples are connected to power supply. Three different voltage levels of $7.4 \mathrm{~V}, 9 \mathrm{~V}$ and $12 \mathrm{~V}$ are applied to e-textile samples. After the samples reached stable flow regime, the current passing through and the resistance of the powered e-textile samples were acquired using Keithley ${ }^{\circledR} 2000$ 61/2Digit multimeter.

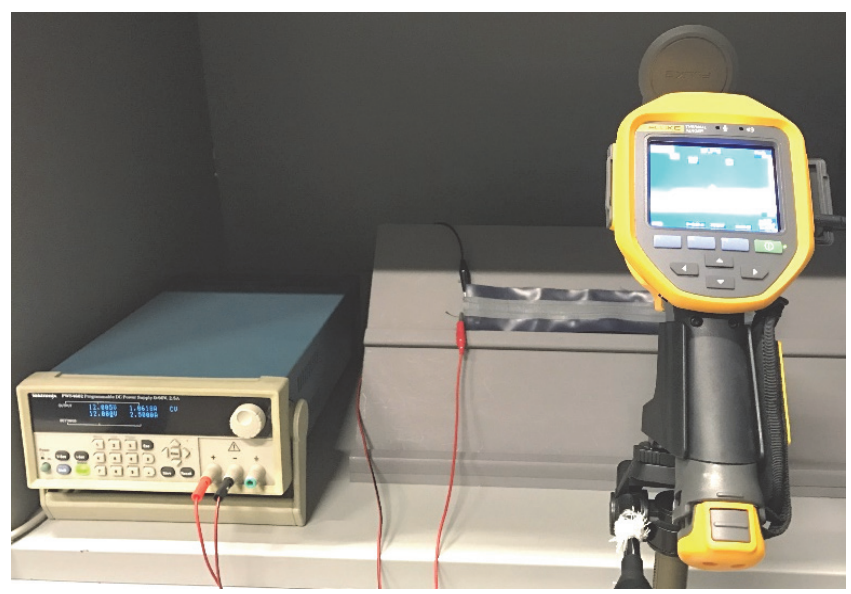

Figure 3. Testing set up for measuring current over powered etextile structures 
Table 2. Experimental set-up for production and testing of welded e-textiles.

\begin{tabular}{|c|c|c|c|c|c|}
\hline Fabric & Welding tape & $\begin{array}{c}\text { Welding } \\
\text { temperature }\left({ }^{\circ} \mathrm{C}\right)\end{array}$ & $\begin{array}{c}\text { Feeding } \\
\text { speed (ft/min) }\end{array}$ & Resistance $(\Omega / m)$ & $\begin{array}{c}\text { Applied } \\
\text { voltage (V) }\end{array}$ \\
\hline Polyamide & WT2 & 500 & 1,5 & $5.4,18,30,51$ & $7.4,9,12$ \\
\hline Polyamide & WT2 & 500 & 3 & $5.4,18,30,51$ & $7.4,9,12$ \\
\hline Polyamide & WT2 & 550 & 3 & $5.4,18,30,51$ & $7.4,9,12$ \\
\hline Polyamide & WT3 & 450 & 8 & $5.4,18,30,51$ & $7.4,9,12$ \\
\hline Polyamide & WT3 & 450 & 12 & $5.4,18,30,51$ & $7.4,9,12$ \\
\hline Polyamide & WT3 & 500 & 8 & $5.4,18,30,51$ & $7.4,9,12$ \\
\hline Polyamide & WT3 & 500 & 12 & $5.4,18,30,51$ & $7.4,9,12$ \\
\hline Polyester & WT1 & 500 & 3 & $5.4,18,30,51$ & $7.4,9,12$ \\
\hline Polyester & WT1 & 550 & 6 & $5.4,18,30,51$ & $7.4,9,12$ \\
\hline Polyester & WT2 & 500 & 3 & $5.4,18,30,51$ & $7.4,9,12$ \\
\hline Polyester & WT2 & 500 & 6 & $5.4,18,30,51$ & $7.4,9,12$ \\
\hline Polyester & WT2 & 550 & 3 & $5.4,18,30,51$ & $7.4,9,12$ \\
\hline Polyester & WT2 & 550 & 6 & $5.4,18,30,51$ & $7.4,9,12$ \\
\hline Polyester & WT3 & 500 & 8 & $5.4,18,30,51$ & $7.4,9,12$ \\
\hline Polyester & WT3 & 500 & 12 & $5.4,18,30,51$ & $7.4,9,12$ \\
\hline Polyester & WT3 & 550 & 8 & $5.4,18,30,51$ & $7.4,9,12$ \\
\hline Polyester & WT3 & 550 & 12 & $5.4,18,30,51$ & $7.4,9,12$ \\
\hline
\end{tabular}

\section{RESULTS AND DISCUSSION}

\subsection{Statistical Analysis Results}

\subsubsection{Effects of manufacturing parameters on average current of welded e-textiles}

In order to investigate the effects of factors on the resultant current measured, main effects of factors are analyzed using MiniTab® 17 standard statistical package program, and the results are as presented in Figure 4 below.

As seen in Figure 4 above, effects of Welding Tape Type, Fabric Type and Welding Temperature on average measured current are insignificant, presenting general averages regardless of the type or level of the factor applied. As a result of the limitations previously mentioned, processing temperature and feeding speed levels were chosen depending on fabric and welding tape types, and welding tape was selected depending on fabric type, thus their effects were insignificant. Significant difference was not observed between the samples made of polyester and polyamide. This was rather expected due to similar thermal conductivity values of the fabrics selected $\left(0.15-0.4 \mathrm{Wm}^{-1} \mathrm{~K}^{-1}\right.$ for polyester and $0.2-0.4 \mathrm{Wm}^{-1} \mathrm{~K}^{-1}$ for polyamide), which would otherwise interfere with the actual current level measured. However, effects of electrical resistance of the conductive yarn and applied voltage appear to be highly significant. It is known that the measured current on the welded e-textile is highly dependent on the electrical resistance of the conductive yarn and applied voltage, rather than the welding tape, fabric and welding parameters applied during preparation of the e-textile samples. As expected, lower resistance of the conductive yarn and higher voltage applied resulted in higher average measured current throughout the welded e-textile.

\subsubsection{Boxplots of measured actual current}

In order to better present the effects of manufacturing factors on the average measured current, data collected throughout the experimental study is separately presented for each factor using Boxplots as given in Figures 5-7.
Boxplot is a graphical summary of the distribution of a sample that shows its shape, central tendency, and variability. The colored box in the middle represents middle $50 \%$ of the data, on which horizontal lines from bottom to top represent 1st quartile, 2nd quartile (median), and 3rd quartile, respectively. Vertical lines, namely upper and lower whiskers, present maximum and minimum data points, respectively. Data presented as * shows outliers which are more than $3 / 2$ times further than the closest quartile.

Figure 5a presents boxplot of actual current data according to welding temperature. All temperature levels resulted in similar distributions around their median, having skewed shapes presenting higher number of values condensed below the median while a spread distribution over their median. Comparison of the medians presents similar centers showing similar average currents, presenting that change in welding temperature did not significantly affect actual current measured. The longer upper whiskers show that the average measured current was much spread at higher temperatures, regardless of the welding temperature applied.

Figure $5 \mathrm{~b}$ presents boxplot of measured actual current data according to feeding speed. All speed levels resulted in similar distributions spread over their medians showing higher variation at higher actual current levels measured, as can be seen from the skewed shape and longer upper whiskers among all feeding speed levels studied. In general, it can be concluded that there is no significant difference between the current values of e-textile samples produced under different welding temperature and feeding speed levels. For this reason, for formation of e-textile system containing stainless steel yarns, welding parameters studied under this work (temperature and feeding speed) are seen to be dependent factors on the type of used materials. This can be attributed to the selection of welding parameters via preliminary experiments before setting the experimental design. 


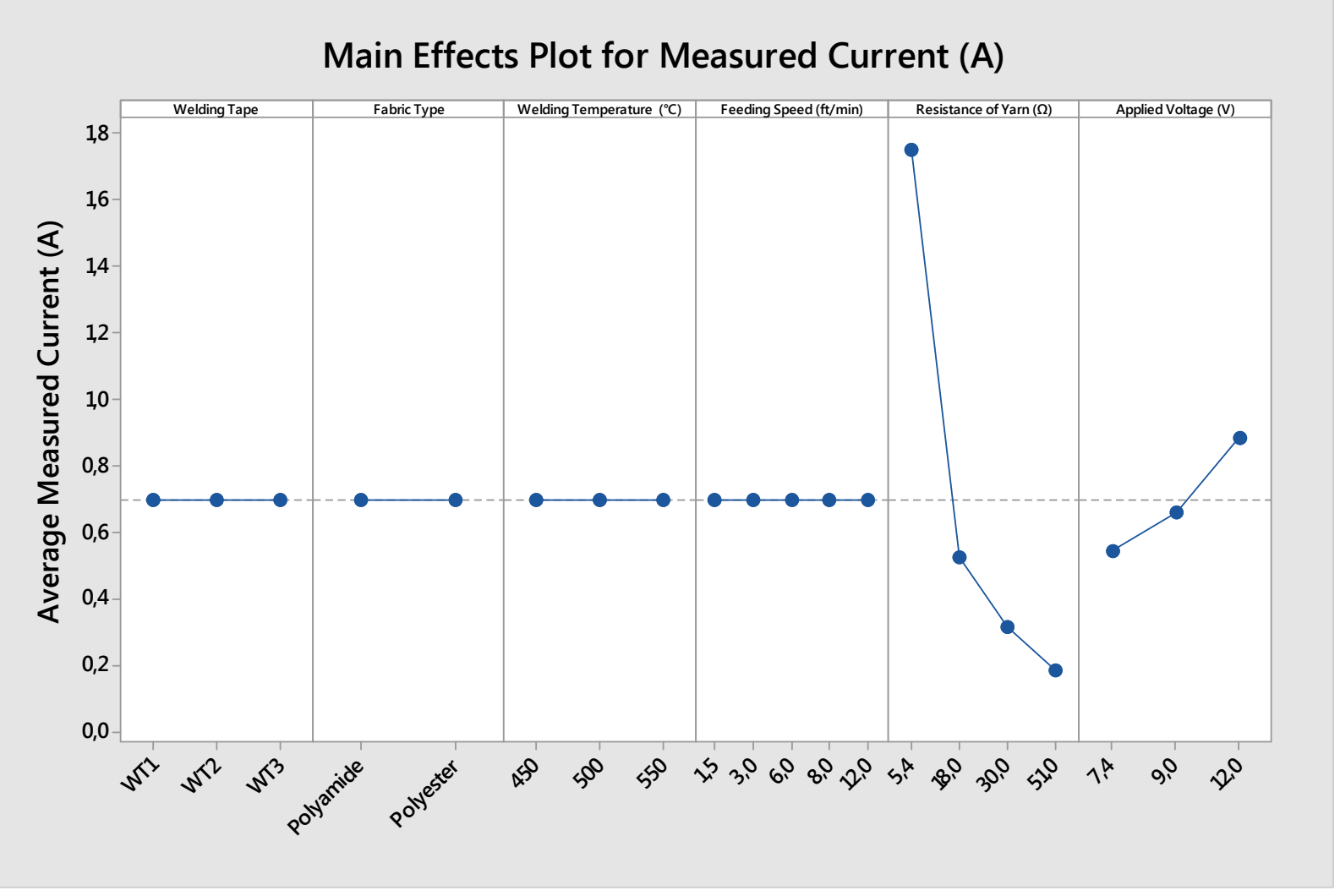

Figure 4. Main effects of factors on average measured current on welded e-textiles

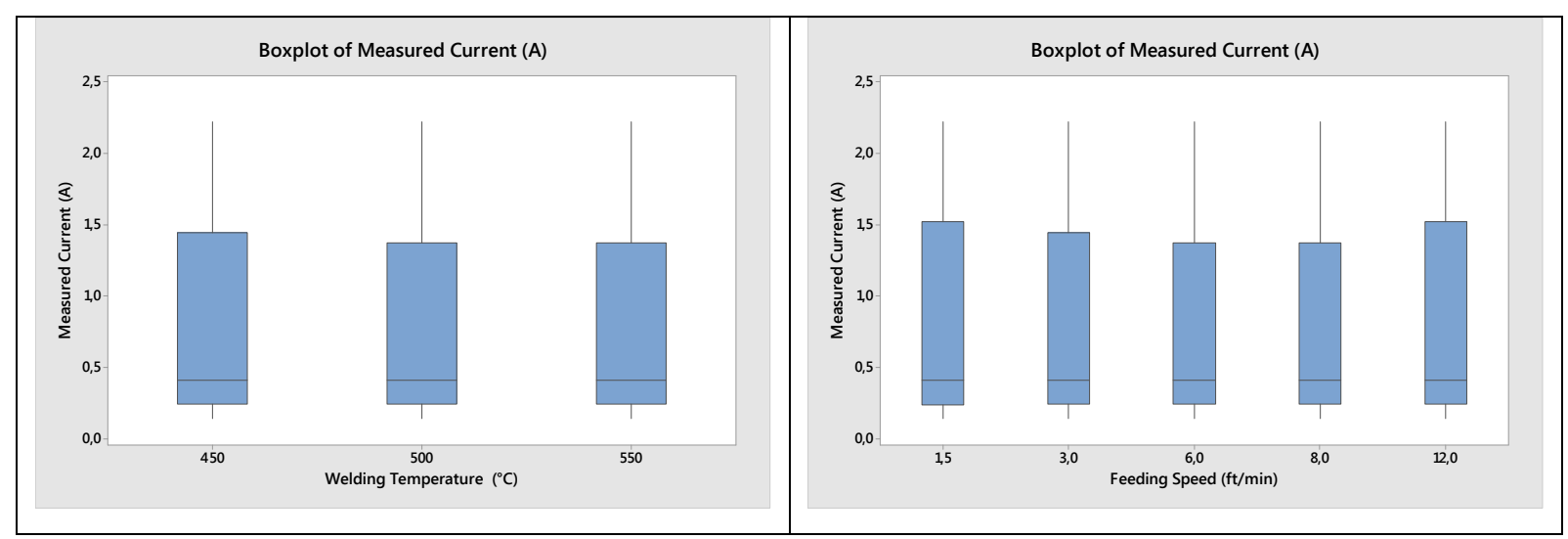

Figure 5. Boxplot of actual current data according to welding temperature and feeding speed

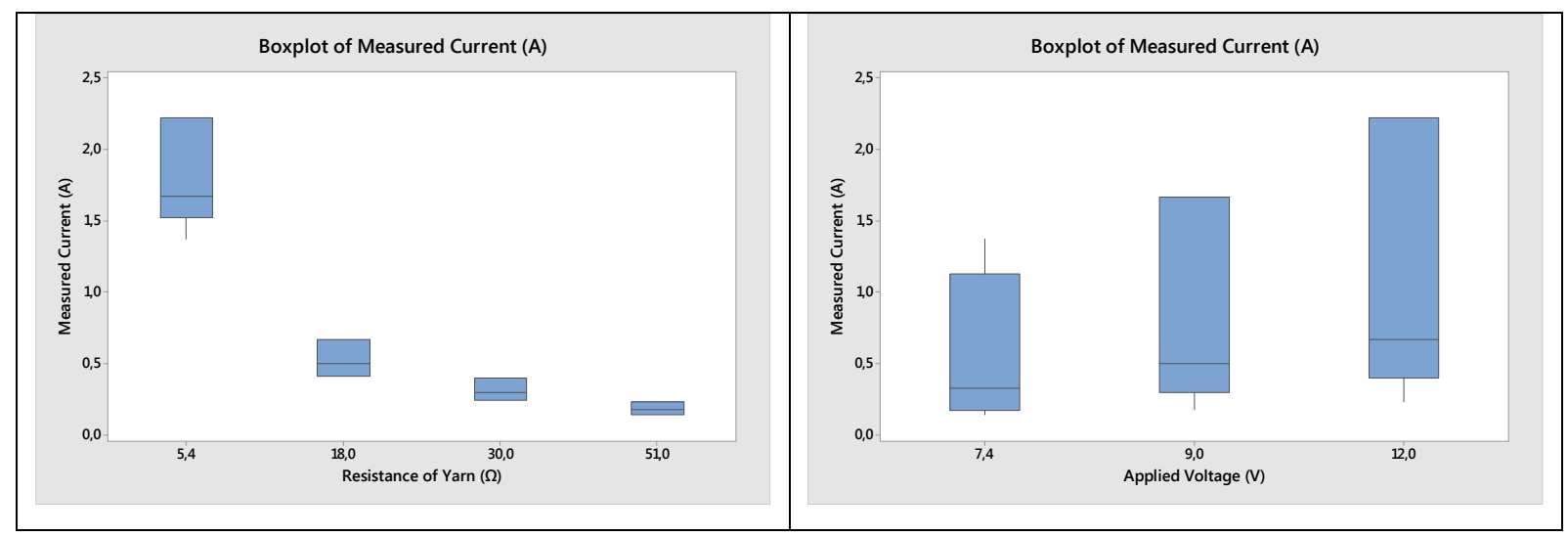

Figure 6. Boxplot of actual current data according to electrical resistance of conductive yarn and applied voltage 
Figure 6 presents boxplot of measured current data according to resistance of conductive yarn and applied voltage. It is apparent from the figure that change in resistance of conductive yarn significantly changes the distribution of measured current, as presented by varying centers and tallness of the individual boxplots. Increase in resistance caused a significant decrease in average measured current. Lower resistance values indicated skewed distribution while presenting higher number of values condensed below the median with a spread distribution over their median, especially for $5.4 \Omega / m$ resistance level. On the other hand, distribution of actual current appears to be more uniform at higher resistance values. It is apparent that higher resistance of conductive yarn resulted in lower actual current readings with very high accuracy. It is also apparent from the figure that change in applied voltage significantly changes the distribution of actual current measured on the welded area, as presented by varying centers and tallness of the individual boxplots. For all among the voltage levels studied, the distribution appears to be skewed showing higher number of values condensed below the median while a spread distribution over their median, especially for $12 \mathrm{~V}$ of applied voltage. Distribution of actual current appears to be more uniform around the median at the applied voltage level of $7.4 \mathrm{~V}$, accompanied with a longer upper whisker presenting more spread higher current values, however, longer lower whiskers for both $9 \mathrm{~V}$ and $12 \mathrm{~V}$ applied voltage levels show that lower actual current data was much spread.

Figure 7a presents boxplot of actual current data measured according to welding tape type. All tapes present similar distributions around their median, showing that the effect of using different welding tapes on average surface temperature is limited. Boxplots for all three welding tapes have skewed shapes presenting higher number of values condensed below the median while a spread distribution over their median. Comparison of the medians show that WT1 tape offers slightly lower actual current variance than WT2 and WT3. The long upper whiskers and short lower whiskers present that the lower values are very close to one another while the highest values as well as outliers are spread around the higher actual current levels measured.

Figure $7 \mathrm{~b}$ presents boxplot of measured surface temperature data according to fabric type. Both fabrics present similar centers showing similar average measured currents. The skewed shapes and longer upper whiskers show that there is higher variation when the actual current measured is high, regardless of the fabric type.

\subsubsection{ANOVA for effects of manufacturing parameters on measured current of welded e-textiles}

In order to present the effectiveness of the factors studied in this work on average measured current, ANOVA analysis was made. Details of ANOVA are given on the Table 3 below.

It is apparent from data on Table 3 that Resistance of Yarn and Applied Voltage are the two very effective factors (with $p$ values $<0.05$ ) affecting measured current, while effects of Welding Tape Type, Fabric Type, Welding Temperature and Feeding Speed are insignificant. This was rather expected as the measured current on the yarn is highly dependent on the electrical resistance of the conductive yarn and applied voltage, rather than the welding tape,

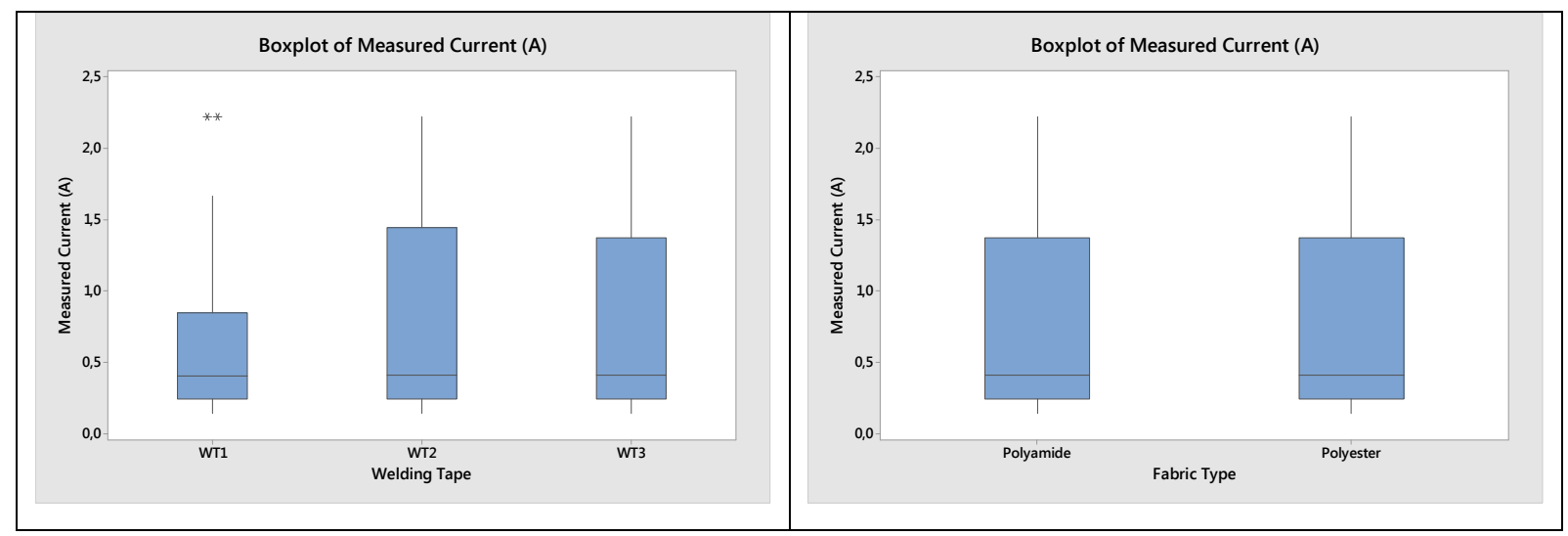

Figure 7. Boxplot of actual current data according to welding tape and fabric type

Table 3. ANOVA results for Average Measured Current

\begin{tabular}{llllll}
\hline Source & DF & Adj SS & Adj MS & F-Value & P-Value \\
\hline Welding Tape & 2 & 0.007 & 0.0033 & 0.18 & 0.837 \\
Fabric Type & 1 & 0.0000 & 0.0000 & 0.00 & 0.967 \\
Welding Temperature $\left({ }^{\circ} \mathrm{C}\right)$ & 2 & 0.001 & 0.0004 & 0.02 & 0.981 \\
Feeding Speed $(\mathrm{ft} / \mathrm{min})$ & 4 & 0.0000 & 0.0000 & 0.00 & 1.000 \\
Resistance of Yarn $(\mathbf{\Omega} / \mathrm{m})$ & 3 & 103.219 & 34.4062 & 1834.59 & 0.000 \\
Applied Voltage $(\mathrm{V})$ & 2 & 5.627 & 2.8134 & 150.02 & 0.000 \\
Error & 210 & 4.013 & 0.0188 & & \\
Total & 224 & 112.867 & & & \\
\hline
\end{tabular}

${ }^{*}$ level of significance: $95 \%$; ${ }^{2}$ : $96.63 \%$ 
fabric and welding parameters applied during preparation of the e-textile samples. Moreover, the possible limited effects of welding parameters were further eliminated due to selection of welding parameters based on preliminary trials [1]. The insignificance of the effect of the fabric type on average surface temperature was probably due to usage of similar thermoplastic fabrics, namely polyester and polyamide, with very similar thermal conductivity characters (thermal conductivity of $0.15-0.4 \mathrm{Wm}^{-1} \mathrm{~K}^{-1}$ for polyester and 0.2-0.4 $\mathrm{Wm}^{-1} \mathrm{~K}^{-1}$ for polyamide, respectively).

\subsubsection{Interaction effects of significant parameters on measured current of welded e-textiles}

The interaction effects of resistance of conductive yarn and applied voltage on average measured current are presented side by side on contour plot and surface plot in Figure 8 . Such plots are effective in aiding observation of levels of more than one effective parameter on an expected response.

As shown in Figure 8, increase in resistance of conductive yarn decreases measured current among the levels studied. Increase in applied voltage increases average measured current, as expected. In order to reach higher average measured current levels demanded by the e-textile samples, higher voltage must be applied to e-textile samples manufactured using conductive yarns with low resistance values. It is also apparent from Figure 8 that in order to reach an average current value over $1 \mathrm{~A}$, resistance must be relatively lower than $10 \Omega / m$ regardless of the applied voltage levels applied in this study. Furthermore, at applied voltage of $12 \mathrm{~V}$ or more, selection of highly conductive yarn with very low resistance will be demanded to reach actual current level of $2 \mathrm{~A}$ or more. It is apparent that for reaching a targeted level of actual current, applied voltage and resistance of conductive yarn must be carefully selected.

\subsubsection{Desirability}

In order to investigate the effectiveness of the selected parameters in reaching a desired actual current value, a desirability analysis was constructed using MiniTab® 17. A desirability (D) value of 1 shows perfectly reaching the target, while lower $D$ values present weaker estimations. The selected desired actual current was $1.75 \mathrm{~A}$. The desirability map is presented in Figure 9 below.

As shown in Figure 9, when the targeted actual current is 1.75 A, within the levels of the factors selected among the study, it is possible to reach an actual current of $1.7495 \mathrm{~A}$ by manufacturing welded e-textile sample using conductive yarn having resistance of $5.4 \Omega / \mathrm{m}$, WT2 welding tape and polyamide fabric at $500{ }^{\circ} \mathrm{C}$ of welding temperature and applying voltage of $9 \mathrm{~V}$. The achieved current of $1.7495 \mathrm{~A}$ presents a desirability value of $D=0.99972$ which is very close to 1 . This very high desirability value and very precise estimation of the actual current temperature present the effectiveness of the production method and accuracy of selecting levels of parameters for reaching a desired current within the average actual current levels studied.

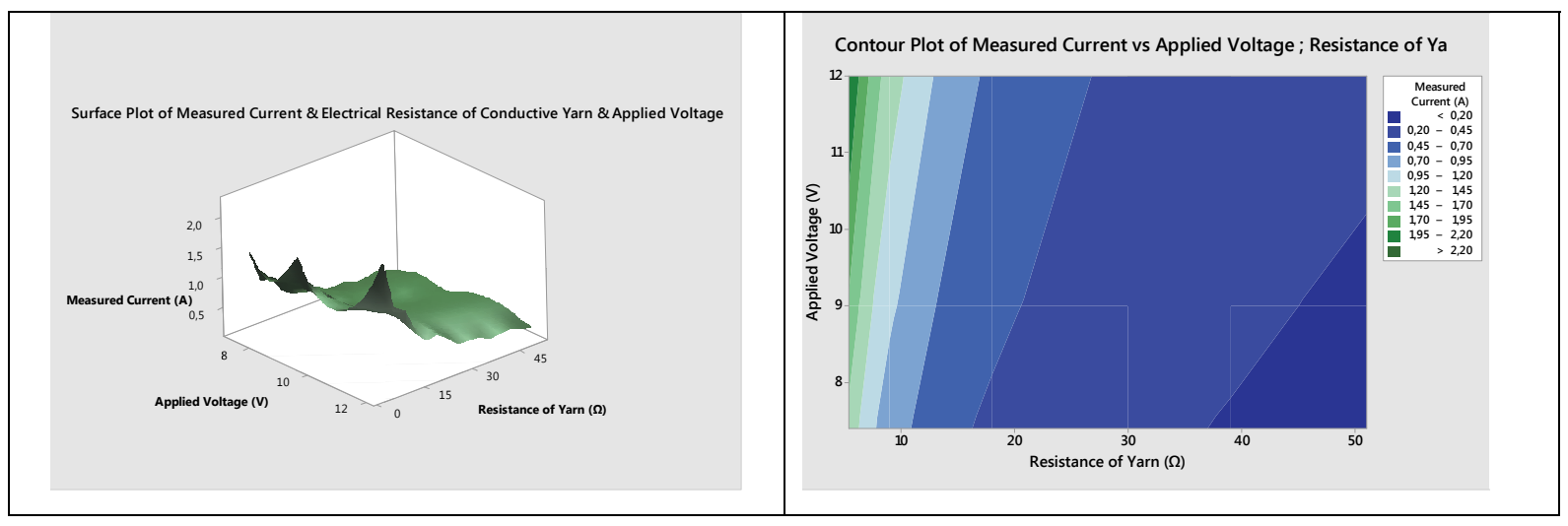

Figure 8. Plots for interaction effect of resistance of conductive yarn and applied voltage on average measured current

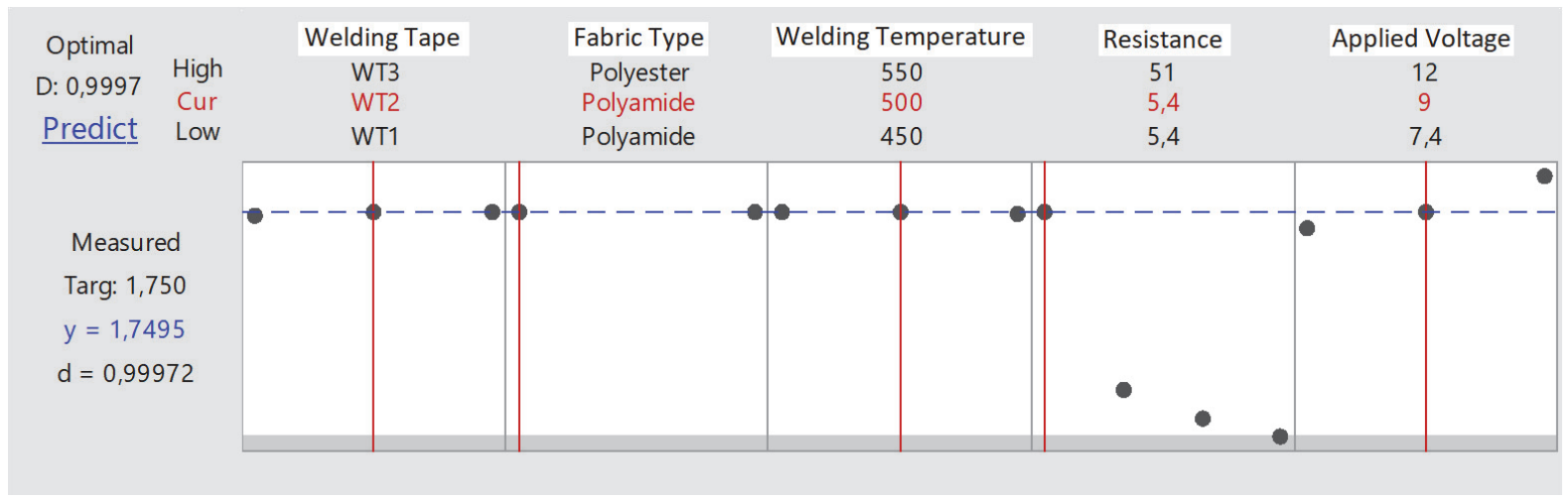

Figure 9. Desirability map for a target actual current of $1.75 \mathrm{~A}$. 


\section{CONCLUSION}

Offering high level of protection and insulation without sacrificing comfort, welding is a promising technique in manufacturing of e-textile based wearable electronics with high quality. Depending on the material type, available machinery and expectations of the end-user, many factors affecting final product quality must be considered while designing a welding process for e-textile production. In this study, in order to create an e-textile power transmission system, three different types of multi-layered breathable, waterproof and windproof welding tapes and polyester or polyamide textile fabrics were brought together with stainless steel conductive yarns under different welding process parameters. Those welded e-textiles systems were powered with different voltages and the resulting actual currents on e-textiles were measured after each sample reached thermal regime visually proven by real-time observations at a specially constructed setup. The relationship between welding parameters and actual

\section{REFERENCES}

1. Kursun Bahadir, S. \& Jevsnik, S. (2017). Optimization of Hot Ai Welding Process Parameters for Manufacturing Textile Transmission Lines for E-textiles Applications: Part I: Electro-conductive Properties. Textile Research Journal, 87(2), 232-243. https://doi.org/10.1177/0040517516629140.

2. Kursun Bahadir, S. \& Sahin, U.K. (2018) A Wearable Heating System with a Controllable E-Textile-Based Thermal Panel. In J.H. Ortiz (Ed.), Wearable Technologies (pp. 175-194). London: Intechopen Ltd. ISBN 978-953-51-6081-6.

3. You, D., Gao, X. \& Katayama, S. (2014). Monitoring of High-power Laser Welding using High-speed Photographing and Image Processing. Mechanical Systems and Signal Processing, 49 (1-2), 3952. https://doi.org/10.1016/j.ymssp.2013.10.024.

4. Gao, X., Zhang, L., Liu, J. \& Zhang, J. (2013). A Comparative Study of Pulsed Nd: YAG Laser Welding and TIG Welding of Thin Ti6Al4V Titanium Alloy Plate. Materials Science and Engineering: A, 559 (1) 14-21. https://doi.org/10.1016/j.msea.2012.06.016.

5. Wu, Q., Gong, J.K., Chen, G.Y. \& Xu, L.Y. (2008). Research on Lase Welding of Vehicle Body. Optics \& Laser Technology, 40(2), 420-426. https://doi.org/10.1016/j.optlastec.2007.06.004.

6. Boz, S. \& Erdogan, M.C. (2011). Ultrasonic Energy Usage in Apparel Industry. Textile and Apparel, 21(1), 91-96.

7. He, Q., Yan, R., Kong, F. \& Du, R. (2009). Machine Condition Monitoring using Principal Component Representations. Mechanical Systems and Signal Processing, 23(2), 446-466. https://doi.org/10.1016/j.ymssp.2008.03.010.

8. He, Q., Kong, F. \& Yan, R. (2007). Subspace-based Gearbox Condition Monitoring by Kernel Principal Component Analysis Mechanical Systems and Signal Processing, 21(4), 1755-1772. https://doi.org/10.1016/j.ymssp.2006.07.014.

9. Bartelmus, W. \& Zimroz, R. (2009). A New Feature for Monitoring the Condition of Gearboxes in Non-Stationary Operating Conditions. Mechanical Systems and Signal Processing, 23(5), 1528-1534. https://doi.org/10.1016/j.ymssp.2009.01.014.

10. Violleau, E. (2014). Ultrasonic Welding for Composite Materials. JEC Composites Magazine, 87(1), 92-95.

11. Jana, P. (2011). Assembling Technologies for Functional Garments An Overview. Indian Journal of Fibre \& Textile Research, 36(1), 380387. electrical current were statistically analyzed and discussed. Interaction of applied voltage and resistance of conductive yarn on actual current is presented and discussed using surface and contour plots. In addition, a desirability map was prepared for a targeted actual current of $1.75 \mathrm{~A}$. Statistical analysis of the experimental data showed that applied voltage and resistance of conductive yarn were the highly significantly effective factors on actual current measured on welded e-textile samples. Careful selection of welding parameters depending on fabric type and welding tape type resulted in insignificant effect of all those on actual current measured. Similarly, selection and use of polyester and polyamide fabrics, which have similar thermal conductivity properties, caused similar effects on actual current. E-textile system containing stainless steel yarns with low electrical resistances, under high voltage applied resulted in higher actual current. Desirability map showed that by selection of levels of factors applied throughout the study, a targeted actual current level can be reached with a very high precision of over $99 \%$.

12. Kah, P. \& Martikainen, J. (2011). Current Trends in Welding Processes and Materials: Improve in Effectiveness. Reviews on Advanced Materials Science, 30(2), 189-200.

13. Shishoo, R. (2012). The Global Textile and Clothing Industry. Cambridge: Woodhead.

14. Podržaj, P. \& Simončič, S. (2013). Resistance Spot Welding Control Based on the Temperature Measurement. Science and Technology of Welding and Joining, 18(7), 551-557. https://doi.org/10.1179/1362171813Y.0000000131.

15. Jakubcioniene, Z. \& Masteikaite, V. (2010). Investigation of Textile Bonded Seams. Materials Science (Medziagotyra), 16(1), 76-79.

16. Seram, N. \& Cabon, D. (2013). Investigating the Possibility of Constructing Different Seam Types for Clothing Using Ultrasonic. International Journal of Clothing Science and Technology, 25(2), 9098. https://doi.org/10.1108/09556221311298583.

17. Ghosh, S. \& Reddy, R. (2009). Ultrasonic Sealing of Polyester and Spectra Fabrics Using Thermo Plastic Properties. Applied Polymer Science, 113 (2), 1082-1089. https://doi.org/10.1002/app.30050.

18. Shi, W. \& Little, T. (2000). Mechanisms of Ultrasonic Joining of Textile Materials. International Journal of Clothing Science and Technology, 12(5), 331-350. https://doi.org/10.1108/09556220010377869.

19. Hustedt, M., Stein, J., Herzog, D. \& Meier, O. (2008, May). Laserbased Joining of Technical Textiles for Airbag Production. In Proceedings of the Third World Automotive Congress Plastics-inMotion (1-11). Prague, Czech Republic.

20. Weglowska, A. (2014) Effect of Vibration Welding Parameters on the Quality of Joints Made of Polyamide 66. Polymery, 59(3), 239-245. https://doi.org/10.14314/polimery.2014.239

21. Kursun Bahadir, S., Sahin, U.K. \& Kiraz, A. (2019). Modeling of Surface Temperature Distributions on Powered E-Textile Structures Using an Artificial Neural Network. Textile Research Journal, 89(3), 311-321. https://doi.org/10.1177/0040517517743689.

22. Jevšnik, S., Vasiliadis, S., Kursun Bahadir, S., Grujić, D. \& Stjepanovič, Z. (2016). Applying Heat for Joining Textile Materials. In M. Ishak (Ed.), Joining Technologies (pp. 217-241). London: Intechopen Ltd. http://doi.org/10.5772/64309. 